\title{
Dual Training in Higher Education - A Professional Development Course
}

\author{
Helena Cobos Rius ${ }^{1}$, Andreu Curto Reverte ${ }^{2}$, Betlem Sabrià Bernadó ${ }^{1}$, Josep Fortó Areny ${ }^{1}$ \\ ${ }^{1}$ University of Andorra, ${ }^{2}$ University of Lleida \\ Spain
}

\begin{abstract}
Dual Training, also known as Work Integrated Learning or Co-op is progressively adopted in Higher Education (HE) across the world, as a way to enhance graduates' employability and work readiness. With its appearance in Spain and Andorra, questions are raised about the need to update the professional skills of those intervening in this training model. This paper presents an online professional development training program, destined for $H E$ and business professionals intervening in Dual Training systems in HE. Focused on competency acquisition, this $30 \mathrm{~h}$ professional development course was developed as part of the European project LLL-Transversalis and it is structured in two modules, as well as two workshop meetings. Participants can choose their competency profile and learn more about this HE training system and the role they play in its success through reflective and practical tasks. This training program has been carried out twice so far, successfully certifying 51 participants from Andorra and different Spanish and French regions. Currently, discussions are being held between Universities regarding the possibility to transform the program into an InterUniversity Diploma. Also, a researcher is working on a PhD thesis to provide with a systematic and validated assessment model.
\end{abstract}

\section{Introduction}

Facing a globalized society, where highly skilled human capital is more demanded and with a more competitive labor market, Higher Education (HE) institutions are challenged to meet the territories' social and economical needs [1]. In order to enhance graduates' employability and work readiness, workbased learning - as it is generally referred to in Spain and Andorra; Dual Training - in Higher Education has been gradually developed in European, American and Australian universities [2][3].

This training system enables students to obtain their diplomas through a learning and competency acquisition process based on the pedagogical complementarity, established through a partnership between $\mathrm{HE}$ institutions and the corporate network related to the field. In other words, thanks to this training system, students can develop specific and soft competencies as well as build their professional profile; understanding the corporate world and its needs [4]. According to the European Higher Education Area (EHEA) and the European Commission [5], the teaching paradigm should change towards lifelong learning processes through innovative and dynamic methodologies and Dual Training studies in $\mathrm{HE}$ contributes to do so. However, in order to succeed, all the professionals involved in this training system - academic coordinators, managers, tutors, and professors should have access to information and preparation on how to apply and develop this system in their institution [6].

The experience exposed in this document aims at tackling these training needs, proposing a training program to better understand what Dual Training in $\mathrm{HE}$ is and which competencies are required to ensure its success. The course was created by the University of Lleida, in Spain, as part of the European crossborder project called EFA 162/16 Life Long Learning Transversalis, developed under the Interrreg POCTEFA 2014-2020 program, which funds projects aiming at harmonizing and reinforcing continuous Life Long Learning practices across countries. This project, in particular, was created thanks to a partnership of nine universities from Spain, Andorra, and France [7] which have been working on achieving the following goals:

- To ensure the coherence between the competencies required by the labor market and the training programs in $\mathrm{HE}$.

- To create tools to better orientate the competencies' development and acquisition process.

- To develop the training systems in HE taking into account the corporate world's needs.

The training program presented in this paper was developed following the last project's goal mentioned. Hence, in order to develop or adapt HE programs in a cross-border area, the professionals involved need to understand what Dual Training in $\mathrm{HE}$, which is the corporate reality in their territories and to work on specific skills they will require as to ensure its success. Also, there is a need for consensus on which are the core specificities of the model and 
the professionals required in the cross-border area in the Pyrenees region. This latter achievement aims at facilitating professional mobility between countries and interuniversity Dual Training programs' development. Thus, the interest, importance and potential benefits of this cross-border training $\operatorname{program}^{(1)(2)}$.

\section{Dual Training in HE - profiles review}

During the last decade, various studies have been devoted to analyse the professional profiles needed in Dual Training in HE. However, most of them focus on two of them: the tutors who accompany the trainees (both in school and in the enterprise).

Some authors have highlighted the need for leadership and management and have, hence, identified within their studies the coordinator [8] and manager [9] in this training system. Any HE program organized in a Dual Training approach will have to design a system in which both institutional relationships (alliances university - corporate world) and organizational strategies (recruitment, agreements) are covered by trained professionals. This will ensure the program's success.

Other studies about Dual Training in HE have focused on the professors and how they have to adapt their teaching materials and methodologies to the requirements and specificities of Dual Training [10].

Yet, both the academic and professional - or company - tutors are mainly at the center of the researchers' attention. Many studies revolve around the academic tutor due to his importance and proximity to the trainee. Some research addresses the complexity and need of strategies to integrate both theoretical and practical knowledge and skills [11] while others develop larger studies which enable to identify some of the academic tutor's functions [12].

The professional - company - tutors have also been largely studied. Mainly to identify their training needs given the multiple roles they have to take up [13] and to define and better understand their responsibility for assessing the trainees' competencies acquisition and development [14].

One of Transversalis project's challenges was to carry out a study which gathered and identified all the professional profiles, who are in contact with the trainee during his or her HE studies and who are key to the training system's success.

This research's results provide with the acknowledgment of 5 different professional profiles with their own functions and competencies. The profiles identified were: the coordinator, the

\footnotetext{
(1) University of Andorra gratefully acknowledges the Government of the Principality of Andorra for the 2017 complementary grant to the European POCTEFA 2014-2020 Program, Ref. AUEPXXX-AND/2017.

(2) Helena Cobos Rius acknowledges the research grant from Universitat d'Andorra, AD01 - UdA-2020/2021"
}

manager, the professor, the academic tutor and the professional - or company - tutor. The competencies were established after a research process within the project, developed by the University of Lleida and using the Delphi method. More than 30 experts from Spain, France, and Andorra participated in the Delphi rounds and contributed to identifying and defining the competencies and functions needed in each profile [15].

Thanks to this profiles' study in Dual Training, based on competency recognition, a blended-learning training program was designed and developed, destined to those professionals who take up the role or want to assume one of the profile's responsibilities in a Dual Training program in HE.

Note that, although students are obviously the key to the whole functioning, they were not deemed professional actors yet, and thus, they were excluded from the Delphi method and training program content.

\section{Dual Training in HE - the professional development course}

Among the resources available to enhance employees' competencies, online professional development courses gain popularity and appear to be an effective and preferred training tool among enterprises [16]. According to Schwarts and Bryan [17], professional development or staff development is a term used to refer to a set of opportunities, normally workshops or courses, offered to worker personnel to refine existing skills, acquire new ones to meet changing needs and/or to provide with personal and professional growth. Specifically, professional development programs offer a customized learning experience based on the participants' learning and competency development needs [18]. In the same way, universities should provide their staff with opportunities to develop and acquire new skills. Many studies published worldwide [19][20][21] suggest that professional development activities, mainly online, become more demanded and necessary to answer people's professional perspectives. Also, given the paradigm shift in learning and teaching in Higher Education, faculty members and people involved in these new processes "will require more faculty to learn new skills in order to succeed in the new instructional roles" [22].

Dual Training is one of these innovative methods which aims at contributing to HE's evolution towards a more comprehensive and inclusive training system. Hence, people with new specific skills and knowledge is required in order to successfully implement this training system [23].So, ultimately, the training program pursuits the following goals: 
- Benefit from the advantages and flexibility of autonomous learning, together with personal and fruitful interaction between participants.

- Overcome physical and linguistic borders created by the international profile of the participants, thanks to an online and multilingual learning environment.

- Equip future academic coordinators, managers, tutors, and professors involved in Dual Training with the competencies and knowledge required to adapt their practices to the system.

- Create an international European community with professionals interested in Dual Training in HE.

Given the participants' and the cross-border multilinguistic feature, this professional course is offered in three different languages; Catalan, Spanish and French, and it is monitored and tutored by a Dual Training professional speaking the three of them.

\subsection{Course structure}

Firstly conceived as a blended-learning program, the course had to be adapted due to the Covid-19 and the mobility and gathering restrictions that followed the pandemic's official arrival in March 2020. As a result, the training program has been designed as a $30 \mathrm{~h}$ online course and structured in three different moments; an opening online meeting, which was first meant to be on-site, the online course development, and an online closing meeting, which had to be on-site too.

Both initial and final events now last 3 hours and a half each and the content development is programmed to be done within 23 hours. During these, participants work on two different modules: general knowledge about Dual Training in Higher Education in the Pyrenees cross-border territories (3h) and a profile-specific competency development module which is meant to be completed within $20 \mathrm{~h}$ of work.

Once they have finished module 1, participants coming from different territories can choose the professional profile they are interested in, according to their professional training needs: academic coordinator, manager, professor, academic tutor, or company tutor. Each profile, as it will be thoroughly explained in the next section, is divided into five specific competencies (C), each of which can be developed in 4 hours. Figure 1 synthesizes and clarifies the professional course's structure. Chronologically speaking, the professional course is scheduled and programmed to last 4 months. Figure 2 shows how the submissions and competency work are organized.

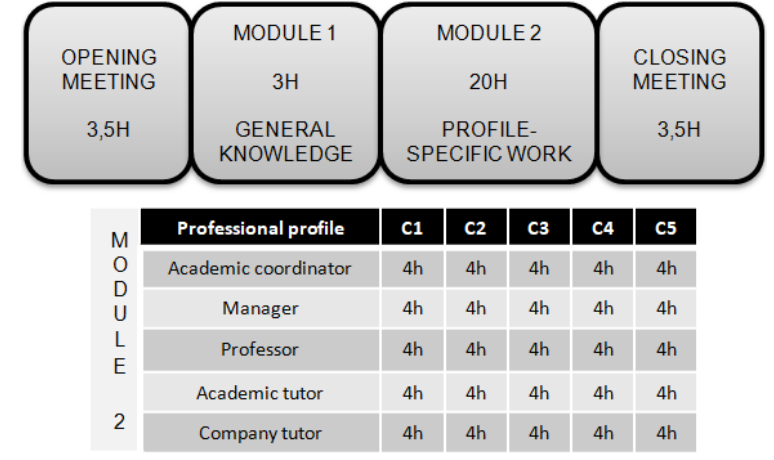

Figure 1. Course structure

\begin{tabular}{|c|c|}
\hline DEADLINE & EXPECTED WORK DONE \\
\hline Week 0 & Online initial meeting \\
\hline Week 1 & Module 1 \& Needs' survey \\
\hline Week 3 & Competencies 1 \& 2 (8 hours) \\
\hline Week 7 & Competencies 3 \& 4 (8 hours) \\
\hline Week 10 & Competency 5 (4 hours) \\
\hline Week 13 & Catch-up submissions without feedback \\
\hline Week 16 & Online final meeting \& Satisfaction survey \\
\hline
\end{tabular}

Figure 2. Course calendar

Note that, in order to obtain the diploma certifying the participants' course achievement, the final tasks (FT) of each competency (mentioned in the next sub-section) and both initial and final survey must have been submitted before the training program's completion.

\subsection{Course content}

As mentioned above, the program starts and finishes respectively with an opening and closing meeting. During the initial session, participants are asked to sign up in the platform, complete an initial needs and expectations survey, test the functionalities, familiarize themselves with the course layout, and in the end, attend a conference about Dual Training in Higher Education. On the other hand, during the final meeting, participants who have achieved and completed the course are asked to complete a satisfaction survey, share their experience with the team and they are invited to join a professional community devoted to developing cross-border Dual Training in HE, called unidual.net.

Regarding the core of the training program, it is divided into five different profiles, each composed of five competencies to develop through practical tasks. Participants are provided with the necessary documents to achieve the goals set in each competency and are asked to submit their work in a personal folder located in the platform. Currently, the course content is the following: 
Module 1 - What is Dual Training in Higher Education? This module is addressed to all participants, no matter their professional profile, and it focuses on exploring the dual training systems existing in the Pyrenees' cross-border regions. It gives an overview of the challenges and benefits, as well as the main actors and keys to its success. This module takes $3 \mathrm{~h}$ to complete on average and does not ask for a final task. This is the theoretical part.

Module 2 - Profile-specific competency development. This module is divided into five profiles. The participants must select the profile they want to work on and progressively complete the tasks presented (starting by Competency 1 and ending with Competency 5). This module takes $20 \mathrm{~h}$ to complete; $4 \mathrm{~h}$ per competency on average. This duration may vary depending on the participants' IT, analytical, and writing skills. All the competencies and tasks are hereunder mentioned by profiles so as to provide a complete overview of the training program's content and topics addressed. The information is presented in tables 1 to 5 .

Table 1. Academic coordinator course content

C1. Design and implementation of the Dua Training System in Higher Education

Leadership, resistances, system's incoherence and program transformation (FT)

$\mathrm{C} 2$. Foreseeing educational trends and their applicability

Horizon reports' analysis, future jobs and preparing a speech addressed to students (FT)

C3. Generating and maintaining key alliances

Empathy chart, partnership and preparing a speech addressed to companies (FT)

C4. People and resources management

Team building, functions' distribution and critical coordination situations analyse (FT)

C5. Assessing dual training system's design, processes, and results

Global assessment, comparative analysis and

systems' assessment design (FT)

Table 2. Manager course content

C1. Diploma content and its relation to the professional sector.

Career opportunities, basic knowledge and preparing a presentation addressed to professors about Dual Training (FT)

C2. Managing the processes related to Dual Training in Higher Education.

Effective management, dual training contracting and practical case - counseling an enterprise (FT)

C3. Integrating and highlighting the system's opportunities and benefits.
Empathy chart, communication strategies and practical case - press conference (FT)

C4. Counseling the stakeholders enabling effective management.

Effective communication, project management and defining the rules for an effective deployment of Dual Training System (FT)

C5. Driving continuous improvement processes and quality.

Functions' and responsibilities' distribution and critical management situations analyse (FT)

Table 3. Professor course content

C1. Understanding the relation between the discipline content and the corporate world

Creativity and education, career opportunities and specific subject competencies' analyse (FT)

C2. Didactics to generate meaningful learning

Meaningful learning, active methodologies and Horizon reports' analysis (FT)

C3. Using the opportunities that the learning contexts create

Effective communication, educational tendencies and practical case - classroom management in Dual Training programs (FT)

C4. Integrating students' work experiences in class

Experiences' integration, developing critical thinking and preparing a presentation addressed to students explaining learning integration (FT)

C5. Adapting the assessment to Dual Training programs

Value judgments, assessment through short stories and assessment tools' transformation (FT)

Table 4. Academic tutor course content

C1. Understanding the relation between the diploma content and the corporate world

Initial researches about HE programs, HE competencies' analyse and career opportunities chart creation (FT)

C2. Understanding the business culture of the professional sector related to the diploma

Corporate culture, professional tendencies and Canvas Business Model creation (FT)

C3. Using the opportunities that the learning contexts create

Steve Jobs' experience, knowledge integration in HE courses and practical task - preparing a seminar about theoretical and practical knowledge integration (FT)

C4. Mentoring, accompaniment, and personalized orientation

What does being a tutor mean?, orientation and tutoring tools and solving hypothetical scenarios when tutoring (FT) 


\begin{tabular}{l}
$\begin{array}{l}\text { C5. Adapting the assessment to Dual Training } \\
\text { programs }\end{array}$ \\
\hline $\begin{array}{l}\text { Value judgments, doubts' resolution and } \\
\text { assessment tools analyse and creation (FT) }\end{array}$ \\
\hline
\end{tabular}

Table 5. Company tutor course content

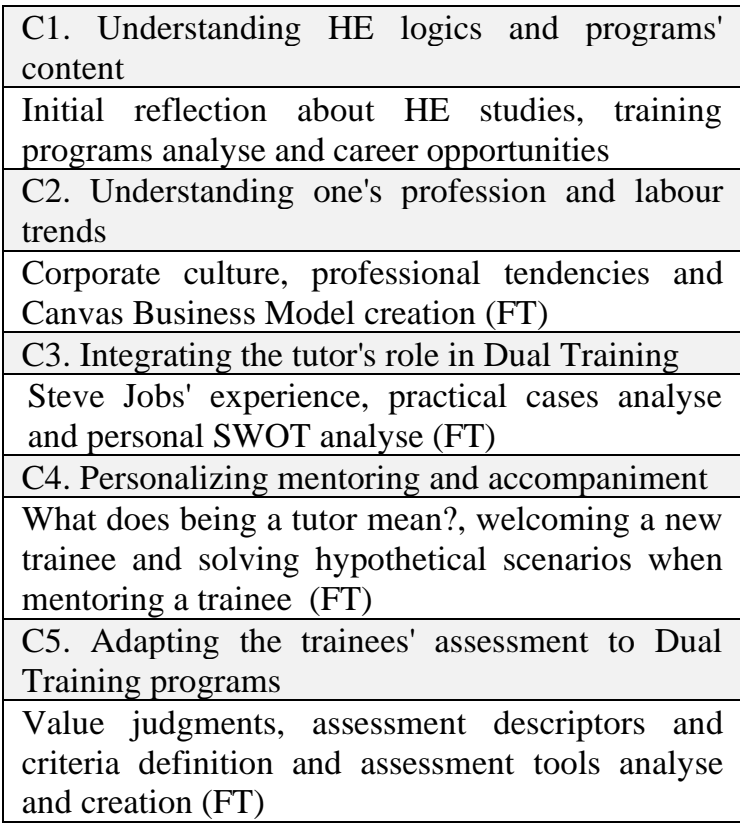

Generally, each competency is worked through two to four tasks which are meant to be done in order. Task 1 is an introductory one: thanks to a short clip, image or text, participants are asked to reflect upon some concepts or situations in which the competency worked is necessary. Task two (or three if there are 4 tasks) aims at exploring more complex situations or aspects regarding the competency worked and, finally, the final task - which is compulsory if the participant wants to obtain the diploma - asks the participants to apply the knowledge and skills they have gained thanks to the other tasks in order to create a final product, useful and applicable in their professional reality (e.g. an engaging speech, an assessment rubric, a informative presentation, etc).

\subsection{Course assessment}

Each competency block proposes a final task which aims at assessing the participant's competency and knowledge acquisition. A full-time researcher, member of the faculty team and expert in Dual Training is responsible for tutoring and correcting the participants' work.

Once the participants send their work, this person is responsible for correcting and giving qualitative and extended feedback about the content and the final product obtained through the final task. Also, the tutor suggests and encourages the pursuit of the course. After completing, sending and getting back all final tasks reviewed, participants receive a certificate stating that they have successfully completed the training course, specifying the profile chosen and its content.

On the other hand, participants are asked to complete a satisfaction survey once they finish the training program as to assess the course's organization, content and utility.

\subsection{Participants' profile}

Most participants are full-time faculty staff or collaborators in the Universities participating in the LLL-Transversalis project. They all work in different fields (e.g., Education, Nursing, Engineering, Tourism, Law, etc). Interestingly, some of the people following the training program are professionals working in companies, related to the aforementioned sectors, that are interested in becoming stakeholders or are already participating in Dual Training studies in Spain or France. Most of them have little (or no) idea about the challenges, opportunities and benefits of this training system in higher education and want to explore their professional development opportunities.

\subsection{Participants' feedback}

As aforementioned, during the closing meeting, participants are asked to share their experiences and point out possible improvements. From April 2020 to June 2020, the first edition of this training program took place. From the initially registered 50 people, a little more than $50 \%$ completed the course $(n=27)$.

In the closing event, most participants reported a positive and interesting experience; they had the feeling to have gained a better understanding of the system and how they could contribute to its deployment. After receiving different informal information, the research team deemed important to structure and collect qualitative evidence on the participants' opinion. Thus, a series of online interviews were carried out from June to July 2020. Twelve participants were interviewed and shared their opinion and view about the training program. During these interviews, some aspects were deemed improvable such as the interaction between the participants, which was almost inexistent, the tasks' instructions which were sometimes insufficient to correctly understand the task and, finally, the course workload - participants claimed they had spent more hours working on the content than it was supposed to, according to the course structure presented. The following table (table 6) presents the reflections which support the above statement. 
Table 6. Participants' comments on interaction, instructions and workload

Interaction between participants
"I had the feeling I was alone (...) it is true that
there was not many interaction" (INT5)
"In an online program it is difficult to participate
(...) the bond breaks easily (...) Maybe the debate
part should be done differently" (INT1)
Tasks' instructions
"There are tasks which can be understood in
many different ways... There was an activity
which I had to watch what the others did (...) it
was not clear" (INT8)
"Sometimes (...) it was not clear what was asked
or the work we had to create" (INT10)
Training program's workload
"I had to work more than I expected (...) Some
workload indications were quite right but some
activities needed more than an hour to be done"
(INT2)
"The total dedication for this course is longer
when summing up all the activities (...) I think that
the workload is wrongly calculated." (INT3)
"It is quite long, given that this is added to our
normal professional workload. (...) I think I
missed concrete directions and information about
it during the first meeting" (INT4)

Despite of these improvable aspects, the global assessment and opinion was positive, as all the interviewed people agreed on the quality and potential of this cross-border professional development program.

"Very interesting content (...) the topics too because I deem them applicable (...) it enables us to observe what should I change if I worked in a Dual Training program. (INT11)

"There were many aspects or questions which were not only at a professional level but they made your reflect from a personal point of view (...) I really liked starting with a video or a short clip from a film" (INT6)

"What I liked the most is the philosophy of this training program, I mean, it is not a course in which you give us some theoretical content that we follow and there is a final test and that's it. (...) I have found it quite skill-building" (INT12)

"The fact of being able to stop, think, analyse and see how are you doing things, what you could do, examine if it can be adapted or not, what can be improved... For me it has been a very enriching and necessary exercise." (INT7)

Given the positive feedback and interest of participants in the training program, a second edition of the course was organized and took place from March 2021 until July 2021, with some adaptations and modifications, following the 1st edition's assessment and observations. Specifically, online synchronous meetings were organized as to foster participants' interaction, detailed instructions were provided as to improve tasks' comprehension and, finally, some activities were deleted or re-design as to adjust and reduce the program's total workload. Also, a defined calendar with deadlines was introduced, as well as the possibility of working only on the final tasks as to obtain the certificate - hence adapting the program to the individual's time disposal.

In this second edition, 53 people registered, with a higher participation of professional workers coming from the corporate sector and 24 people successfully finished the professional development course. Figure 3 shows a comparison between participants successfully trained in both editions, by profiles.

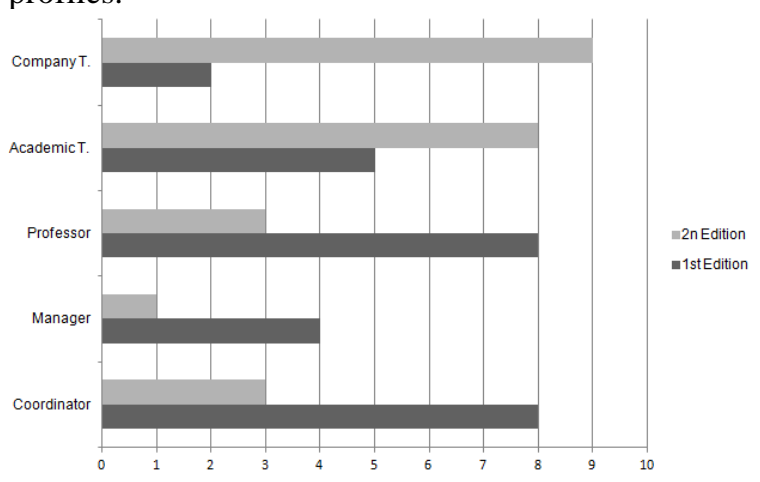

Figure 3. Participants trained by profiles

Interestingly, the tutors' willingness to be trained has grown during the last year. In the following section, some discussion is presented as to explain why this can have happened.

Finally, the satisfaction assessment of this second edition is currently going on. The data will be analyzed during the following months and a team meeting should take place in September 2021 to discuss any additional changes or re-design.

\section{Conclusion}

On a serious note, it has been progressively acknowledged that higher education in Spain and Andorra needs to evolve towards co-operative and work-based university programs, there isn't a solid political framework in these countries that regulates this training system in Higher Education yet, 
contrary to their northern neighbors; France and Germany [24]. Recently in Spain, the University Ministery has published a proposal to review the higher education decree to incorporate the possibility to deploy dual training studies in Bachelor's and Master's degrees.

At the same time, the Spanish Workers' Statute has been modified in order to acknowledge the "dual training" contract [25]. One of the requirements for universities to establish a partnership with enterprises is that those professionals chosen to mentor and assess the students need to be trained and have notable experience in their professional sector. That is why this project and, especially, this professional development training program has an evident potential to foster interest and implication in developing this system in these countries. Also, that could explain why in the second edition, the presence of both academic and company tutors raised considerably compared to last year.

Another point which should be highlighted is the presence, since the beginning of this scholar year, of a researcher who is devoting her $\mathrm{PhD}$ thesis to create and develop a systematic and quantitative assessment model for this course. The need for validated and effective assessment tools should ensure the program's quality and continuous improvement as well as to provide Spanish and Andorran universities with a "professional training kit" with both content and assessment material.

By participating in this online course, professionals from the academic and business world from different territories have the chance to meet, discuss their points of view about students' needs, realize how $\mathrm{HE}$ institutions and companies can work together to foster employability and competency acquisition and, ultimately, become part of an international network interested in this topic.

On the other hand, and taking into account LLLTransversalis' goals, which focus on harmonizing and developing common HE practices in the crossborder Pyrenees regions, this professional development program is currently being transformed into an Inter-University HE Diploma. This means that, probably next year, if participants want to obtain an Inter-University (and International) Diploma certifying the professional training received, they will have to enroll in a complementary module, with additional materials about France's laws regarding Dual Training. Once they will have both finished the professional development program and the additional module, they will receive a $\mathrm{HE}$ Diploma valid and recognized by French and Spanish universities.

This seeks to strengthen the bonds between HE institutions and business networks in both sides of the Pyrenees region, hence pushing policymakers to establish regulated frameworks to ensure the well- functioning of these partnerships at an international and cross-border level.

\section{References}

[1] Pavlin, S. (2016). "Considering University-Business Cooperation Modes from the Perspective of Enterprises", European Journal of Education, 51(1), pp. 25-39.

[2] Jackson, D. (2018). "Developing graduate career readiness in Australia: Shifting from extra-curricular internships to work-integrated learning", International Journal of Work-Integrated Learning, 19(1), pp. 23-35.

[3] Graf, L. (2017). "Work-based higher education programs in Germany and the US: Comparing multi-actor corporatist governance in higher education", Policy and Society, 36(1), pp. 89-108.

[4] Beraza J.M. and Azkue I. (2018) "Diseño de un itinerario de formación dual: universidad-empresa en gade", Journal of Management and Business Education, 1(1), pp. 53-68.

[5] European Commission (2018). "Council Recommendation on Key competences for Life Long Learning". Official Journal of the European Union 2018/C $189 / 01$.

[6] Coiduras, J. L. (2013). "Universidad y empleo: escenarios complementarios en educación superior", Formación XXI. Revista de Formación y Empleo, 22, Dual Training Monograph.

[7] LLL-Transversalis (2020). Action 6. Ingeniería de la formación dual. INTERREG EFA 162/16 LLLTransversalis; https://etransversalis.univ-perp.fr/es/ingenie ria-de-la-formacion-dualidad-entre-formacion-inicial-conti nua (Access Date: 8 July 2021).

[8] Sachs, J., Rowe, A., and Wilson, M. (2016) "2016 Good Practice Report-Work Integrated Learning (WIL)" Canberra, ACT, Australia: Office of Learning and Teaching.

[9] Smith, C., and Worsfold, K. (2015) "Unpacking the learning-work nexus: 'Priming' as lever for high-quality learning outcomes in work-integrated learning curricula" Studies in Higher Education, 40(1), pp. 22-42.

[10] Whelan, M. B. (2017) "Academic work-integrated learning (WIL): reengaging teaching focused academics with industry" Journal of Teaching and Learning for Graduate Employability, 8(1), pp. 172-188.

[11] Peguera, M.C., Curto, A., Ianos, M.A. y Coiduras, J.L. (2021) "Evaluación de narrativas en formación dual docente: diseño y experimentación del instrumento SCAN", Revista de Investigación Educativa, 39(1), pp. 111-130, DOI: 10.6018/rie.4215271

[12] Chenerie, I. (2019) "Caractériser le tutorat dans les formations en alternance : objectifs poursuivis et activités menées par les tuteurs académiques en Institut 
Universitaire de Technologie", Toulouse: Université Toulouse Jean Jaurès.

[13] Davy, N. and Frankenberg, A. (2019) Typology of Apprenticeships in Higher Vocational Education. Apprenticheships Q+.

[14] Jackson, J., Jones, M., Steele, W., and Coiacetto, E. (2017) "How best to assess students taking work placements? An empirical investigation from Australian urban and regional planning." Higher Education Pedagogies, 2(1), pp. 131-150.

[15] Curto, A. (2021) "Los profesionales de la formación dual en el ámbito universitario: identificación de perfiles, funciones y competencias" ( $\mathrm{PhD}$ Thesis) University of Lleida.

[16] Karnouskos, S. (2017) "Massive open online courses (MOOCs) as an enabler for competent employees and innovation in industry", Computers in Industry, 91, pp. 110

[17] Schwarts, R. and Bryan, W. (2002) "What is professional development?" New Directions for Student Services, 84 , pp. 3-13.

[18] Hartshorne, R. et al., (2020) "Special Issue Editorial: Preservice and Inservice Professional Development During the COVID-19 Pandemic", Jl. of Technology and Teacher Education, 28(2), pp. 137-14.

[19] Erkinovna, G. (2020) "Methodological Recommendations on the Organization of Teaching a Foreign Language based on Blended Learning at the Professional Development Courses for Pedagogical Staff from Higher Education Institutions (HEIS)." European Journal of Research and Reflection in Educational Sciences, 8(10), pp. 170-177.

[20] Brancato, V. (2003) "Professional Development in Higher Education." New Directions for Adult and Continuing Education, 98 (Special Issue), pp.59-66.

[21] Lidolf, S. and Pasco, D. (2020) "Educational Technology Professional Development in Higher Education: A Systematic Literature Review of Empirical Research." Front. Educ. 5, pp. 1-10, 10.3389/feduc.2020.00035.

[22] Lieberman, D. and Guskin, A. (2017) "The Essential Role of Faculty Development in New Higher Education Models" To Improve the Academy, 21(1), pp. 257-272.

[23] Paris, G., Tejada, J. and Coiduras, J. (2014) "La Profesionalización de los Profesionales de la Formación para el Empleo en Constante [In]definición en Europa." Profesorado. Revista de Currículum y Formación, 18(2), pp. 268-283.

[24] Mondragon University (2018) "La formación dual universitaria: una labor compartida", ORIENTAGUNE; https://www.mondragon.edu/documents/20182/562551/for macion-dual.pdf (Access Date: 8 July 2021).
[25] Moreno Gené, J. (2021) "El contrato para la formación dual universitaria: una primera aproximación a la espera de su imprescindible desarrollo reglamentario", E-Revista Internacional de la Protección Social, 6(1), pp. 188-234. 